\title{
Alternative splicing of the neural cell adhesion molecule gene generates variant extracellular domain structure in skeletal muscle and brain
}

\author{
Joanne Thompson, ${ }^{1}$ George Dickson, ${ }^{1}$ Stephen E. Moore, ${ }^{1}$ Hilary J. Gower, ${ }^{1}$ Wendy Putt, ${ }^{1}$ James G. \\ Kenimer, ${ }^{2}$ C. Howard Barton, ${ }^{1}$ and Frank S. Walsh ${ }^{1,3}$ \\ ${ }^{1}$ Institute of Neurology, London WCIN 3BG UK; ${ }^{2}$ Laboratory of Cellular Physiology, Food and Drug Administration \\ Bethesda, Maryland 20892 USA
}

\begin{abstract}
Myotube mRNA isoforms of the neural cell adhesion molecule (N-CAM) contain a novel sequence block termed muscle-specific domain 1 (MSD1), which is inserted within the extracellular coding region. Here, we report a characterization of the genomic organization of MSD1 and its pattern of expression within cellular N-CAM RNA and polypeptide species. S1 nuclease protection analyses and sequence analysis of an N-CAM human genomic clone containing MSD1 sequences indicated that MSD1 is comprised of three discrete exons of 15, 48, and $42 \mathrm{bp}$, designated MSD1a, MSD1b, and MSD1c, respectively. Although the MSD1a exon was present in a small proportion of mRNAs from both brain and muscle cells, the entire MSD1 sequence occurred predominantly in mRNAs from differentiated myotube cells. In addition, antiserum raised to a synthetic, MSD1b-encoded peptide sequence was found to stain the cell surface of human skeletal myotubes in culture, whereas myoblasts, fibroblasts, and neural cells were negative. MSD1a, MSD1b, and MSD1c sequences thus arise collectively in N-CAM mRNA and polypeptide isoforms as a result of muscle tissue-specific and developmentally regulated alternative mRNA splicing events. In addition, the occurrence of brain and muscle mRNAs containing only MSD1a indicate that alternative splicing may occur within the MSD region itself to generate further diversity.
\end{abstract}

[Key Words: Exon splicing; genomic structure; synthetic-peptide antibodies; S1 nuclease protection; immunofluorescence]

Received September 20, 1988; revised version accepted January 11, 1989.

The formation of adhesive interactions between cell surfaces is thought to be essential to the processes of cell recognition, sorting, and migration during development, and for the subsequent stabilization and regeneration of tissues in the adult (Edelman and Thiery 1985). A variety of surface glycoproteins involved in cell adhesion has been identified and grouped into $\mathrm{Ca}^{2+}$-dependent and $\mathrm{Ca}^{2+}$-independent families (Takeichi 1988). The best characterized members of the latter family are a group of high-molecular-weight sialoglycoproteins known collectively as the neural cell adhesion molecules (N-CAMs; for reviews, see Cunningham 1986; Edelman 1986; Rutishauser 1986; Nybroe et al. 1988).

$\mathrm{N}$-CAMs are expressed in a wide range of early embryonic tissues but are present predominantly in cells of the nervous system and developing muscle at later stages of development. They have been implicated in a wide range of morphogenetic events, including cell segregation, axonal bundling (Rutishauser et al. 1978; Thanos et

\footnotetext{
${ }^{3}$ Corresponding author.
}

al. 1984), the migration of neurons along glial pathways (Silver and Rutishauser 1984), and in several aspects of myogenesis, including muscle innervation and synaptogenesis (Rutishauser et al. 1983; Covault et al. 1986; Tosney et al. 1986, Rieger et al. 1988). During these processes, the adhesive properties and function of N-CAMs apparently are modulated by the differential expression of variant N-CAM polypeptide isoforms in specific highly regulated patterns.

N-CAM isoform diversity is generated both by alternative splicing and differential polyadenylation site selection within mRNA products of a single complex gene (Hemperley et al. 1986; Barthels et al. 1987; Santoni et al. 1987; Small et al. 1987; Barton et al. 1988). In addition, N-CAM is subject to a variety of post-translational modifications, including glycosylation, phosphorylation, and sulfation (Finne et al. 1983; Hoffman et al. 1982; Sadoul et al. 1983; Rutishauser et al. 1988). Although the chick N-CAM gene has been found to contain at least 19 exons (Owens et al. 1987), alternative RNA processing has been described mainly in relation to 
exons at the $3^{\prime}$ end encoding variable membrane-associated and cytoplasmic polypeptide domains /Cunningham et al. 1987; Small et al. 1987; Barthels et al. 1987). Thus, in chick and mouse brain, three N-CAM isoforms occur with similar extracellular domain structure; two transmembrane isoforms of 180 and $140 \mathrm{kD}$ differ only by the insertion of a domain encoded by a single exon within the cytoplasmic region, whereas a single nontransmembrane species of $120 \mathrm{kD}$ is linked externally to the plasma membrance via a glycosylphosphatidylinositol (GPI) anchor (Gennarrini et al. 1986; He et al. 1986; Barthels et al. 1987).

Transmembrane (140 kD) and GPI-linked $(125 \mathrm{kD}$ and $155 \mathrm{kD}$ ) N-CAM isoforms also have been identified in skeletal muscle (Covault et al. 1986; Dickson et al. 1987; Moore et al. 1987; Barton et al. 1988). However, cDNA sequencing studies have predicted that the membrane-proximal coding regions of muscle GPI-linked mRNA forms contain an additional novel 108-bp region, demonstrating for the first time a tissue-specific variation within the extracellular domain (Dickson et al. 1987). This additional sequence block was found to be expressed in muscle but not brain tissue and hence was termed the muscle-specific domain 1 (MSD1). MSD1 is inserted in human mRNA at a position corresponding to a splice site defined within the chick N-CAM gene, suggesting that it is an alternatively spliced exon. In addition, $\mathrm{S} 1$ nuclease protection studies in the mouse have indicated the presence of an alternative splice site in brain N-CAM mRNAs in a similar location to MSDl in muscle (Barthels et al. 1987). Candidate exon sequences have now been described in this instance (Santoni et al. 1989).

In the present study, we have analyzed the organization of MSDl within the human N-CAM gene and have correlated its pattern of expression in cellular RNAs with that in N-CAM polypeptides on muscle cell surfaces. Here, we present evidence that MSD1 sequence indeed occurs collectively within N-CAM muscle mRNA species as the result of a tissue-specific alternative splicing event and is expressed, as an entire domain, specifically by skeletal muscle myotubes in cell culture. We also report that the MSD1 sequence is encoded by three distinct exons within the N-CAM gene and provide evidence that additional diversity in brain and muscle involving specific N-CAM species also may be generated by alternative splicing of individual exons encoding sections of the domain.

\section{Results}

Tissue and mRNA-specific expression of MSD1 results from alternative RNA splicing

Previous cDNA sequencing studies have indicated that the MSD1 region is inserted into mRNA-coding sequences at a discrete site (Dickson et al. 1987) that can be identified as a splice junction by comparison with the chick N-CAM gene structure (Owens et al. 1987). However, direct evidence showing its presence or absence as a complete unit in cellular mRNA and, hence, its formal identity as an alternatively spliced region is lacking. Therefore, we examined the pattern of MSDl expression in N-CAM RNAs extracted from human embryonic brain and primary cultures of embryonic muscle by $\mathrm{S} 1$ nuclease protection analysis.

A 521-nucleotide single-stranded probe spanning MSD1 was prepared from the previously reported cDNA clone $\lambda 9.5$ (Dickson et al. 1987), hybridized to total RNA, and treated with S1 nuclease. The digestion products then were examined on sequencing gels (Fig. 1A). In line with previous Northern and Western blot studies (Dickson et al. 1987; Moore et al. 1987), a general increase in N-CAM mRNA levels occurred during myogenesis in vitro; however, distinct patterns of MSD1 expression were observed between brain, myoblast, and myotube RNAs. A completely protected band of $521 \mathrm{nu}-$ cleotides, indicating the presence of mRNAs colinear with the whole probe including the MSD1 region, was observed only with differentiated myotube cells in culture. In contrast, human embryonic brain tissue (Fig. 1A, lane 3) and skeletal myoblasts (lane 4) produced predominantly two fragments of 325 and 91 nucleotides, arising as a result of the nonprotection and $S 1$ nuclease digestion of the MSD1 region of the probe. The slight laddering observed with the 91-nucleotide fragment is most likely due to slight $\mathrm{S} 1$ nuclease overdigestion at the ends of this small product. Small amounts of an additional band of 340 nucleotides also were observed in both brain and muscle tissues corresponding to the protection of the $5^{\prime}$ end of the probe and the first $15 \mathrm{bp}$ of MSD1. At later stages of fusion (Fig. 1A, lane 6), two additional bands of 388 and 430 nucleotides were apparent. As shown schematically in Figure $1 \mathrm{~B}$, these additional bands correspond to the protection of the $5^{\prime}$ end of the probe plus the first $63 \mathrm{bp}$ or the whole of MSD1, respectively. The occurrence of the latter fragment indicates a sequence continuity break in some myotube RNAs compared with the $\lambda 9.5$ probe sequence and therefore must represent either a novel inserted sequence or a partial deletion in these mRNAs, at this point immediately $3^{\prime}$ of MSD1. Because another alternatively spliced exon (SEC; Gower et al. 1988) indeed occurs immediately 3' i.e., downstream of MSD1, it seems likely that the 430nucleotide fragment may represent usage of this alternative splicing pathway that leads to production of a secreted N-CAM isoform.

Therefore, these results provide evidence that MSD1 is either present in or absent from mRNAs generated from the single-copy N-CAM gene as a result of alternate exon splicing. In agreement with results from previous Northern blot analyses (Dickson et al. 1987), MSD1 was not found as a complete domain within human embryonic brain mRNAs but was expressed specifically in skeletal muscle mRNAs coincident with the appearance of myotubes. The analysis also predicts that splice junctions exist within MSD1, suggesting that the genomic sequences encoding this region exist as three or more alternatively spliced exons, the first of which, at least, may be individually alternatively spliced into both brain and muscle N-CAM species. 


\section{Genomic organization of MSD1}

The organization of MSD1 within the N-CAM gene was defined by DNA sequence analysis of clones that were isolated from a human genomic library in Charon 35 using the N-CAM cDNA probe $\lambda 9.5$ (Dickson et al. 1987). Figure 2A shows the restriction map of a 14.4-kb clone, $\mathrm{CH} 1 \mathrm{la}$, which hybridized exclusively with an NheI-ApaLI fragment of $\lambda 9.5$, corresponding to $83 \mathrm{bp}$ of the 3 ' region of MSDl. The region of hybridization was localized further to a 5-kb HindIII subfragment at the $3^{\prime}$ end of the clone that was subcloned for sequence analysis.

Two regions of MSDl sequence homology were identified, demonstrating that this domain is present within

A

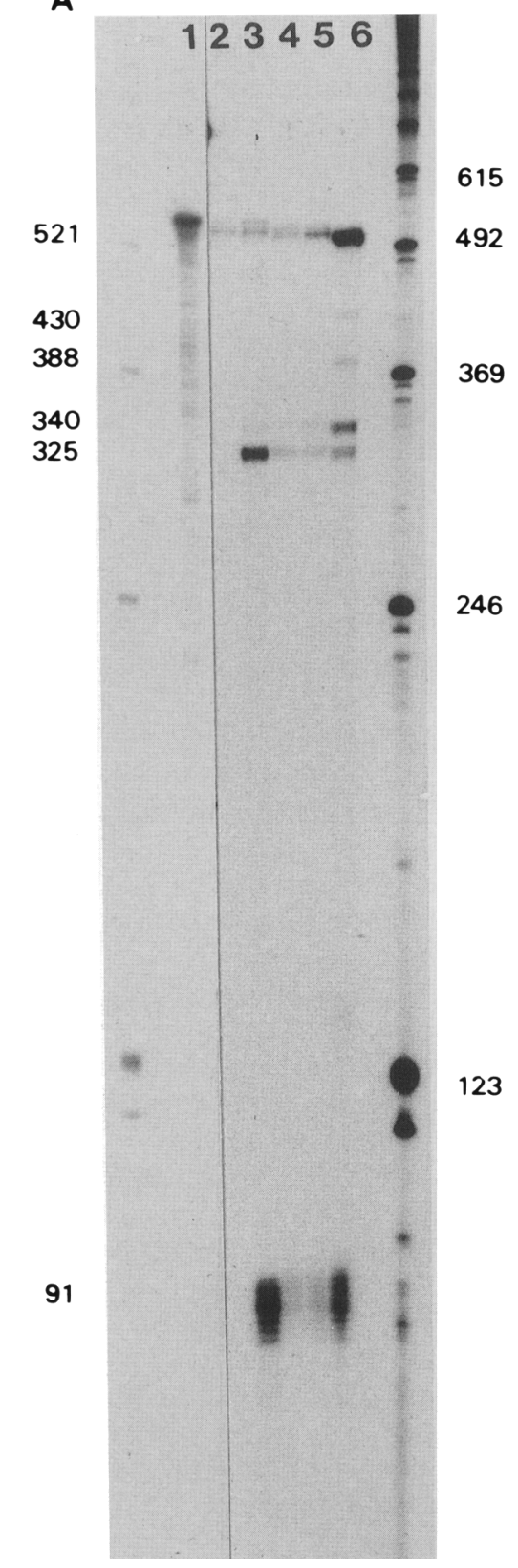

the genome as more than one exon. Sequences of 48- and 42-bp designated exons MSD1b and MSD1c were found to be $100 \%$ identical with bases $16-63$ and $64-105$ of MSD1, respectively. The sequences of the two exons, together with adjacent intron sequences, are shown in Figure 2B. Intron/exon boundaries were identified by comparison with cDNA sequences, and in both cases, donor and acceptor splice junctions were found to conform with statistically predicted consensus sequences (Shapiro and Senepathy 1987). All splice junctions occur between the second and third base of a codon, indicating that omission of any exon by alternative splicing within the MSD1 region would not alter the reading frame of more $3^{\prime}$ sequences. In addition, further sequence analysis has indicated that MSD1c is situated $0.7 \mathrm{~kb}, 3^{\prime}$ of the next N-CAM exon-the recently reported N-CAM SEC exon (Gower et al. 1988).

Previous cDNA sequence data (Dickson et al. 1987) have predicted that an additional 15-nucleotide sequence is present at the $5^{\prime}$ end of MSD1, and the results from $S 1$ nuclease protection analyses presented here have indicated further that a 15-nucleotide sequence corresponding exactly to this region is spliced alternatively as a discrete unit into brain and muscle N-CAM RNA species. Therefore, it is most likely that these 15 nucleotides exist as one or more small exons, which have been termed MSDla. We emphasize, however, that the MSDla sequence is not, in itself, expressed in a muscle-specific manner but only so in the context of the MSD1 region as a whole. Due to its small size and high GC content, we have been unable to detect sequence counterparts specifically in Ch1la or in genomic DNA

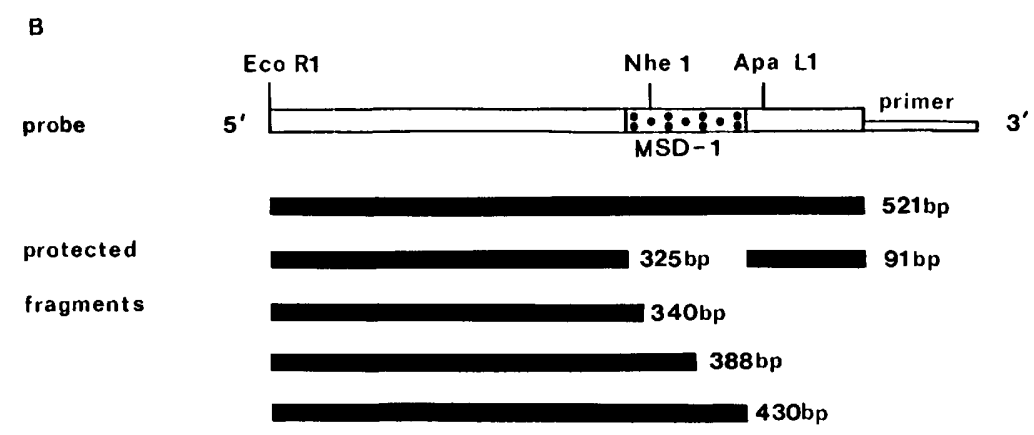

Figure 1. S1 nuclease protection analyses of MSD1 expression in human N-CAM mRNAs. (A) Autoradiograph of a polyacrylamide gel showing separation of protected probe fragments. A single-stranded antisense DNA probe spanning MSD1 was hybridized to total RNA from various sources or to control tRNA and digested with S1 nuclease. (Lane 1) Intact probe; (lane 2) digestion of unprotected probe; (lane 3) probe protection with $50 \mu \mathrm{g}$ total RNA from human brain; (lanes $4,5,6)$ unfused, early fusion, and late fusion human primary muscle cultures, respectively. The laddering observed with the smallest, $91-n u-$ cleotide fragment is not a consistent feature in other analyses and most likely represents slight overdigestion by S1 nuclease. (Left) Lengths (in nucleotides) of the various protected probe fragments; (right) size markers. (B) Schematic representation of the probable location of the various protected fragments (solid bars) relative to the intact probe (open bar) and the internal MSDI sequence block (dotted region). 


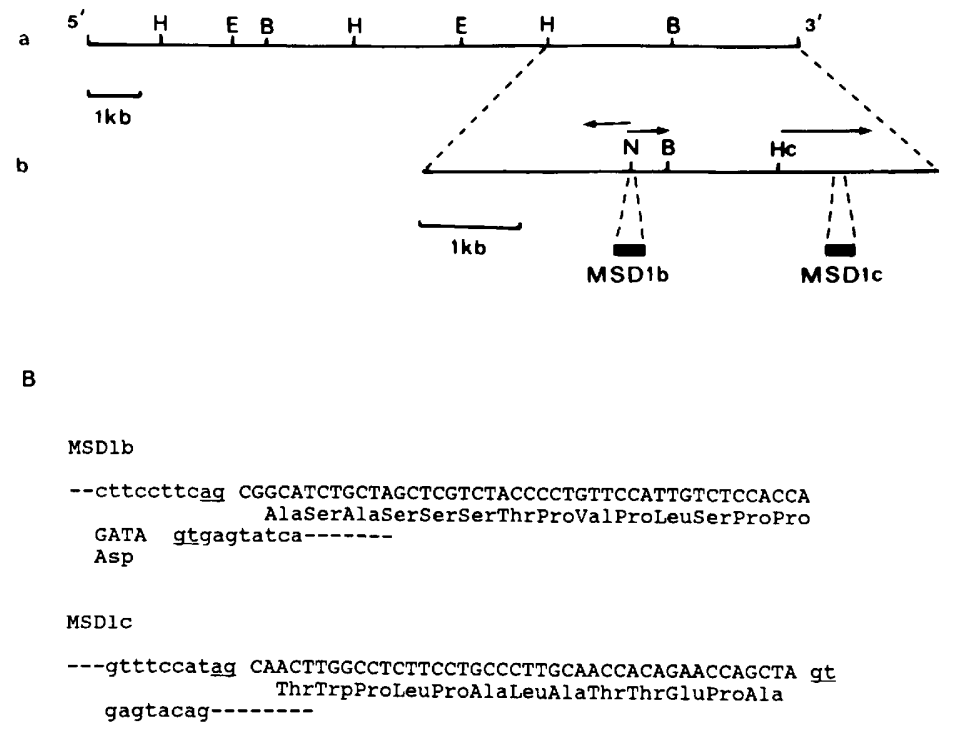

Figure 2. Genomic organization of MSD1. (A) Restriction map of ChllA (a) and a 5-kb subclone of Chl1(b) showing the positions of exons MSDlb and MSDlc. Arrows show the direction and extent of sequencing beginning at the indicated restriction enzyme site. Cleavage sites for restriction enzymes: BamHI (B); EcoRI $(\mathrm{E})$; HindIII $(\mathrm{H})$; and HincII $(\mathrm{Hc}) .(B)$ Intron/exon junction sequences of MSD1b and MSDlc are shown in lower case and uppercase, respectively; $5^{\prime}$ and $3^{\prime}$ splice sites, determined by comparison with $\lambda 9.5$ cDNA sequences, are underlined. Predicted protein sequences encoded by the two exons are indicated below nucleotide sequences. using synthetic oligonucleotide hybridization probes. The preceding exon to MSDla, i.e., the human equivalent of exon 12 as defined in the chick N-CAM gene (Owens et al. 1987), is not present on Chlla, hence, the MSDla sequence occurs within a large genomic DNA region $>12 \mathrm{~kb}$. Recent studies have identified a homolog of the putative human MSDla exon in an appropriate location in the mouse N-CAM gene and described its alternative splicing in brain N-CAM mRNAs (Santoni et al. 1989|. Therefore, we conclude that splice junctions are present within the MSD1 sequence at bases 15/16 and 63/64 and that MSD1 is most likely composed of three exons of 15,48 , and $42 \mathrm{bp}$ at the genomic level.

The S1-nuclease and genomic sequence data of the present study indicate that MSD1 is composed of $105 \mathrm{bp}$ in total, rather than $108 \mathrm{bp}$, as predicted previously from comparison of $\lambda 9.5$ and $\lambda 4.4$ cDNA sequences (Dickson et al. 1987). Analysis of the MSDl sequence in genomic DNA has now revealed that the final 3 bp originally assigned to MSD1 are not contained within exon MSDlc and therefore would be predicted to occur in association with the human equivalent of exon 13 (as defined in the chick N-CAM genel. However, analysis of N-CAM and genomic clones has indicated that these 3 bp cannot be localized to the 5 ' end of exon 13 (Gower et al. 1988), but they are expressed variably at the cDNA sequence level (Dickson et al. 1987; Gower et al. 1988). We would conclude here that either allelic variation exists at the start of exon 13 or possibly an unusually small 3 bp exon that is nonuniformly incorporated into N-CAM mRNAs. In this respect, Santoni et al. (1989) recently have described a similar situation in the mouse N-CAM gene where a potential trinucleotide exon with appropriate flanking consensus sequences has been identified.
$N-C A M$ isoforms containing MSD1 antigen are present specifically on myotubes

As an approach to analyzing the specific cellular expression of N-CAM isoforms containing MSD1-encoded domains, a synthetic peptide corresponding to the 15 amino acids within the MSD1b exon (Fig. $2 \mathrm{~B}$ ) was prepared, conjugated to bovine serum albumin (BSA) and antiserum raised in rabbits. To determine the molecular specificity of the MSDIb antisenum, use was made of mouse 3T3 fibroblast lines that were transfected with full-length human N-CAM cDNA gene constructs, encoding either a $125-\mathrm{kD}$ muscle N-CAM isoform containing MSDl or a $120-\mathrm{kD}$ deletion mutant lacking this region (Gower et al. 1988; F.S. Walsh et al., unpubl.). Both these exogenous genes were introduced into the mouse cells under control of the human $\beta$-actin promoter, yielding constitutive, high-level expression and encoding GPI-linked membrane glycoproteins. A schematic representation of the cDNAs and the derived eukaryotic expression vectors is shown in Figure 3. Transfected $3 \mathrm{~T} 3$ cells expressing MSD1-containing human $\mathrm{N}$-CAM (G4 cells) and the corresponding deletion mutant (A10 cells) were examined for reactivity with the MSDlb synthetic peptide antiserum by immunostaining.

For immunostaining, live cells were subjected to duallabel analysis with a monoclonal mouse antibody recognizing a common human N-CAM epitope (Fig. 4B,E,H,K) and with the rabbit anti-MSDl serum (Fig. 4C,F,I,L). In addition, because N-CAMs are glycosylated extensively and the MSD1 region has been shown recently to carry specific carbohydrate side chains (Walsh 1988), cells were also stained following treatment with highly purified neuraminidase to remove sialic acid polymers that 
Figure 3. Construction of human N-CAM eukaryotic expression vectors. The expression vector $\mathrm{pH} \beta \mathrm{APr}-1$-neo contains 4 $\mathrm{kb}$ of the human $\beta$-actin gene, including $5^{\prime}$-flanking, $5^{\prime}$-untranslated (UT), and the first intron (IVSl), linked at the $3^{\prime}$ splice site to a short polylinker (SaII, HindIII, and BamHI) and followed by an SV40 polydenylation signal (SVpolyA), in addition to ampicillin $\left(A \mathrm{Ap}^{\mathrm{R}}\right)$ and neomycin (SV-neo) resistance genes (Gunning et al. 1987). Sense-orientated full-length human N-CAM cDNAs were inserted in the HindIII site, as indicated. Splice sites are indicated with an asterisk $\left({ }^{\star}\right)$; and initiation (ATG) and termination (TAG) codons of the cDNAs are shown. A linear representation of the encoded polypeptides is given at the base of the diagram. Sequences of MSDl (solid block) and those encoding hydrophobic carboxy-terminal domains (hatched block) are shown. Restriction enzyme sites indicated are EcoRI (E); HindIII $(\mathrm{H}), \operatorname{KpnI}(\mathrm{K})$; SaII $(\mathrm{S}) ; \operatorname{BamHI}(\mathrm{B})$; and $\mathrm{XmnI}(\mathrm{X})$. Full details of cloning substeps are given in Materials and methods.

might mask core MSDlb peptide epitopes. As shown in Figure $4(B, E, H, K)$, both the $G 4$ and A10 cell transfectants express human N-CAM at their surfaces with the level of staining unaffected by neuraminidase digestion. In contrast, only the MSD1-expressing G4 cells were immunostained with anti-MSDlb serum (Fig. 4C,F). In addition, a much increased immunofluorescence signal on G4 cells was observed following neuraminidase treatment (cf. Fig. 4C,F). As would be predicted, the Al0 cells that were transfected with the MSD1-deletion gene construct showed no reactivity with the anti-MSDlb peptide serum (Fig. 4I,K). Parental 3T3 fibroblasts or cells transfected with the wild-type expression vector did not stain with either the mouse anti-N-CAM monoclonal or the rabbit anti-MSDlb antibodies (data not shown). Thus, the anti-MSD1b antiserum exhibited high molecular specifity in terms of immunoreactivity with MSD1containing N-CAM species and additionally was detecting a neuraminidase-sensitive epitope in the native molecule.

At the RNA level, previous Northern blotting studies (Dickson et al. 1987) and the present S1 nuclease protection analyses have indicated that MSD1 expression is regulated in a tissue- and developmental-stage-specific manner. Thus, mRNAs containing all three MSD1 exons are present in differentiated myotube cultures but not in proliferating myoblast cultures or in brain tissue. To attempt to confirm this observed specificity at the level of cellular polypeptide expression, a further series of dual-label immunofluorescence staining experiments

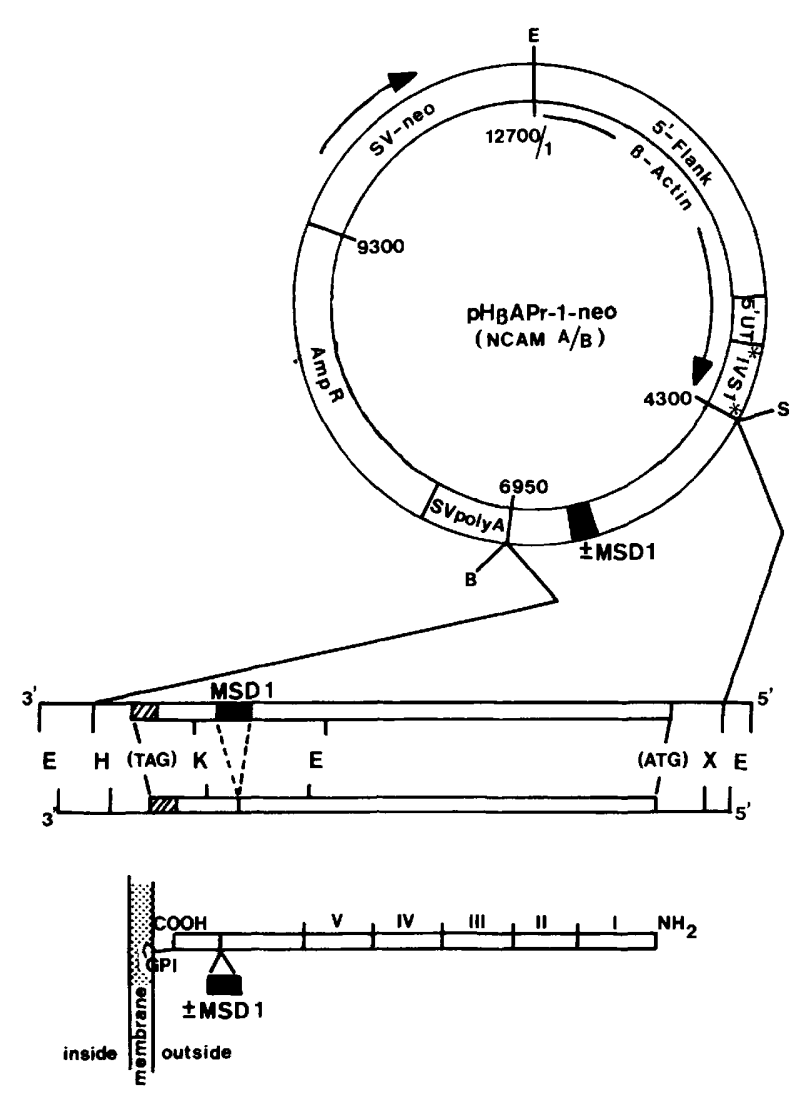

were performed on neuraminidase-treated cultures of human skeletal muscle cells, skin fibroblasts, and dorsal root ganglia (DRG). Human muscle cell cultures were examined at pre- and post-fusion stages and thus contained populations of $\mathrm{N}$-CAM-positive myoblasts and multinucleate myotubes and N-CAM-negative fibroblasts (Fig. 5A,B,D,E). As shown in Figure 5, C and F, only differentiated myotubes, but not myoblast or fibroblasts, showed immunoreactivity with the anti-MSDlb peptide antiserum.

In the case of human DRG, these cultures have a complex cellular composition, containing populations of neurite-bearing sensory neurons with rounded-phase dense cell bodies and prominent nuclei and nucleoli (Fig. $5 \mathrm{G})$, as well as a complement of substrate-attached 'fibroblast-like' cells, which represent predominantly Schwann cells (Dickson et al. 1982; Doherty and Walsh 1989). As shown in Figure 5 (G,H,I), although the majority of both these DRG cell types express N-CAM at their surface, no reactivity was observed with the antiMSD1b antiserum. Finally, no immunoreactivity of anti-MSDlb peptide antiserum was observed with cultures of human skin fibroblasts (Fig. $5 \mathrm{~J}, \mathrm{~K}, \mathrm{~L}$ ) that were stained strongly in dual-label analyses with antifibronectin monoclonal antibody (Walsh et al. 1981), thus controlling the specificity of both the MSD antiserum and the fluorochrome-conjugated anti-rabbit Ig antibodies used as the detecting second antibody.

Thus, at the cellular level, expression of MSD1bearing N-CAM isoforms clearly was restricted to mul- 

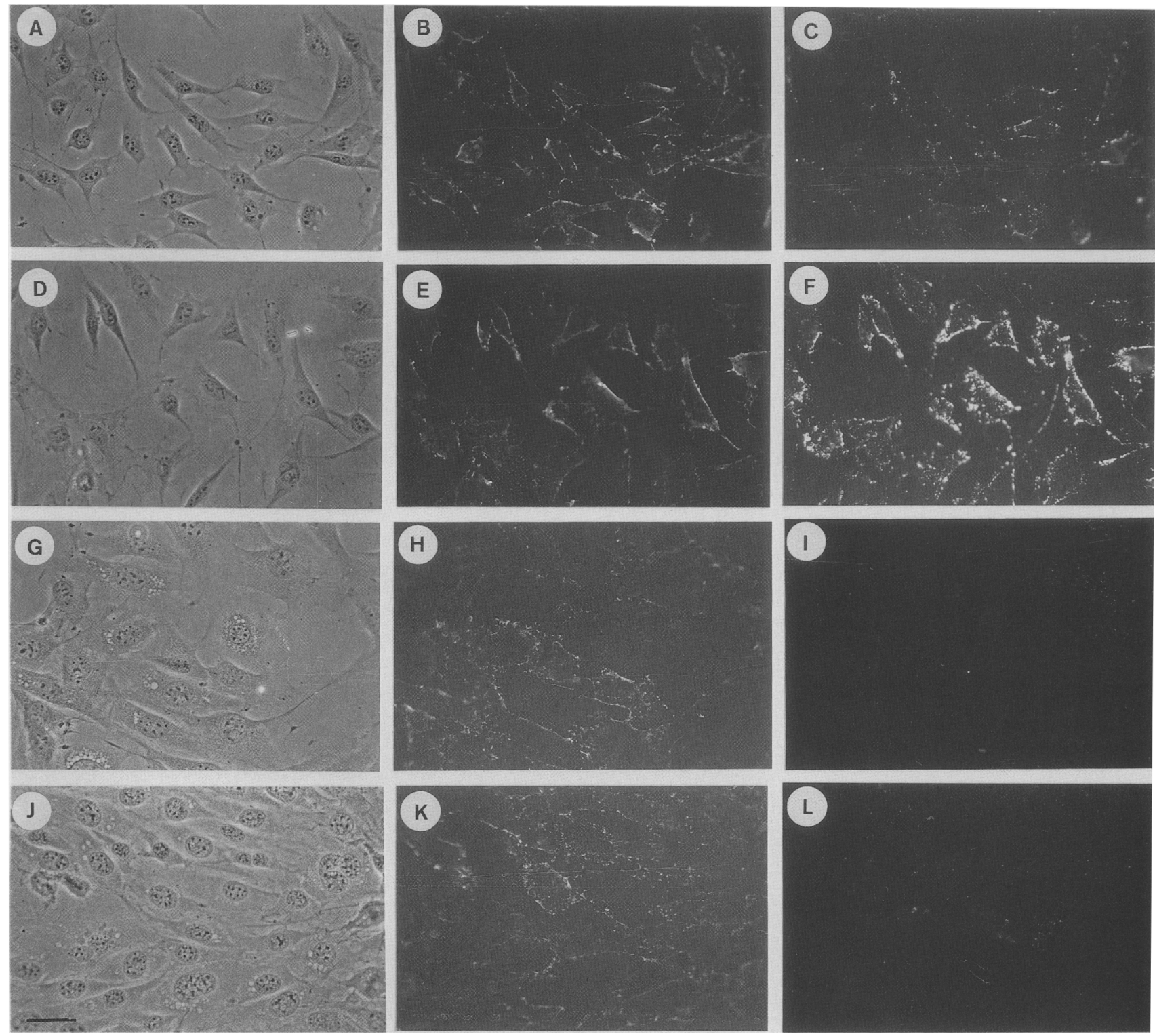

Figure 4. Cells transfected with MSDl deletion mutants of N-CAM do not stain with antiserum to a synthetic MSD1 peptide. NIH-3T3 fibroblasts transfected with wild-type MSD1-containing $(A-F)$ or MSD1 deletion $(G-L)$ N-CAM cDNAs (G4 and A10 cell lines, respectively) were subjected to dual-label immunofluorescence staining with monoclonal anti-N-CAM $(B, E, H, K)$ or polyclonal anti-MSD1b peptide antibodies $\{C, F, I, L)$. Cells were examined with $(D-F, I-L)$ or without $(A-C, G-I)$ prior exposure to neuraminidase. Scale bar, $100 \mu \mathrm{m}$.

tinucleated myotube cells and absent from myoblasts, fibroblasts, and primary cell cultures containing neurons and peripheral glial cells.

\section{Discussion}

Studies in a variety of species have concluded that alternative splicing of a single N-CAM primary transcript gives rise to a number of N-CAM isoforms that differ only within the membrane-associated and cytoplasmic polypeptide domains (Gennarini et al. 1986; Barthels et al. 1987; Cunningham et al. 1987; Small et al. 1987).
However, recent examination of human N-CAM cDNAs has identified a discrete region called MSD1 (Dickson et al. 1987), which is expressed in the extracellular domain of a subpopulation of GPI-linked isoforms. In this study we show that the MSD1 sequence is composed of three distinct alternatively spliced exons within the human $\mathrm{N}$-CAM gene, of 15,48 , and 42 nucleotides, now designated MSDla, MSD1b, and MSDlc, respectively.

In agreement with previous RNA hybridization studies, S1 nuclease protection analyses showed that mRNAs containing all three MSDl exons are the predominant form expressed in differentiated myotubes and that human brain tissue and undifferentiated myoblasts 

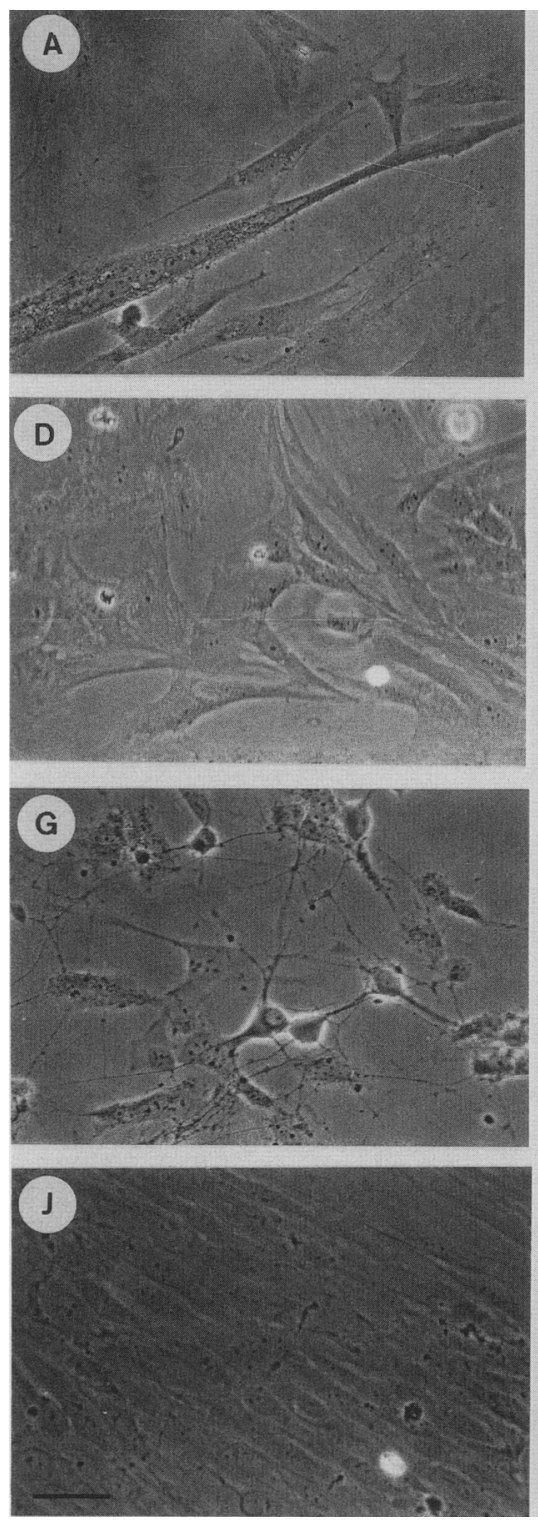
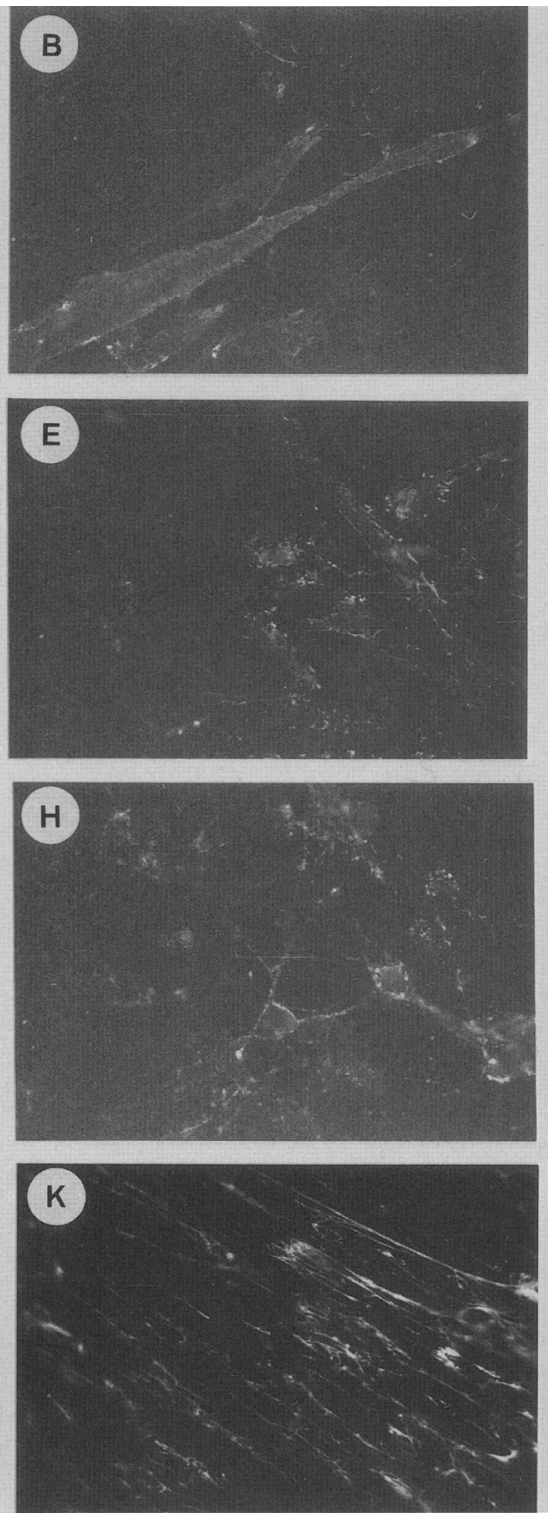
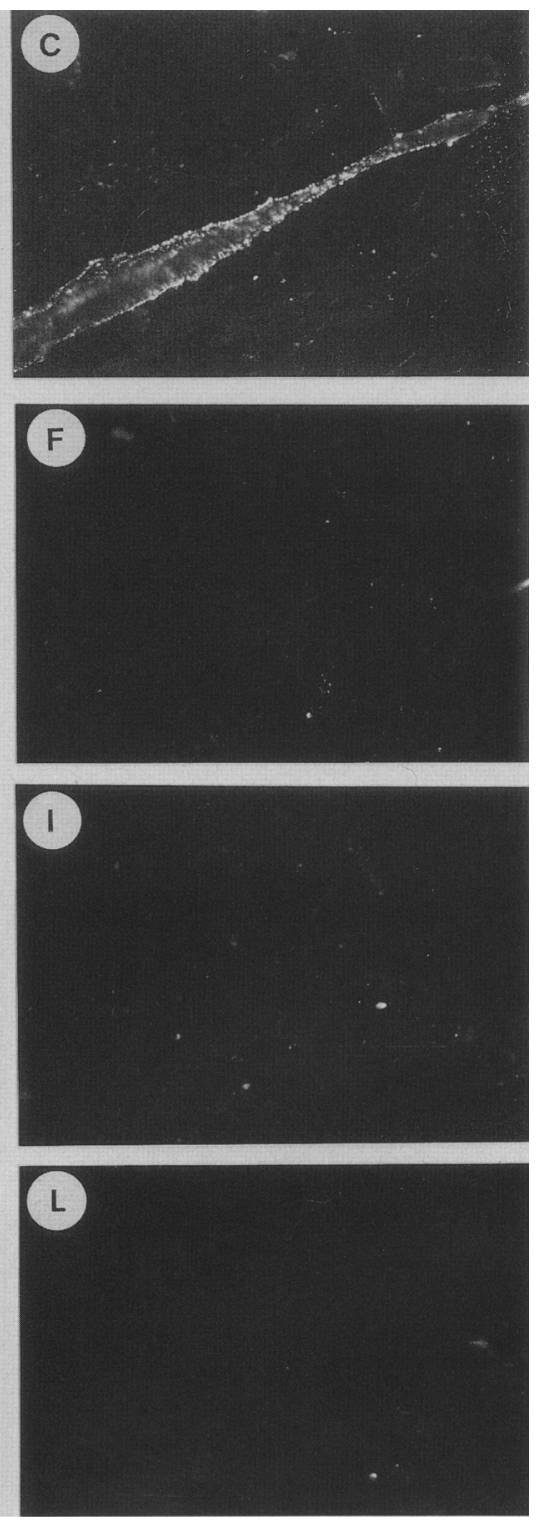

Figure 5. Human skeletal myotubes stain specifically with antiserum to a synthetic MSDlb-encoded peptide. Human skeletal myotubes $(A-C)$, myoblasts $(D-F)$, DRG cells $(G-I)$, and skin fibroblasts $(J-L)$ were treated with neuraminidase and subjected to dual-label immunostaining with monoclonal antibodies to human N-CAM $(B, E, H)$ or fibronectin $(K)$, in conjunction with anti-MSDlb peptide antiserum $(C, F, I, L)$. Scale bar, $100 \mu \mathrm{m}$.

do not express these species. However, small amounts of mRNAs containing MSDla only were observed in all three circumstances, indicating that alternative splicing of this small exon is apparently not a tissue-specific phenomenon. In contrast, however, inclusion of MSDla and MSDIb together or the entire set of three exons in human N-CAM mRNA represent developmentally regulated and tissue-specific alternative splicing pathways.

Using antibodies raised to a synthetic peptide antigen corresponding to sequence encoded by MSD1b, we have shown directly that the expression of N-CAM polypeptides containing MSD1 also is restricted to the cell surface of skeletal myotubes in culture. Previous studies have shown that myotubes express predominantly a GPI-linked N-CAM isoform of $125 \mathrm{kD}$ (Moore et al. 1987), and a full-length MSD1-containing cDNA encoding this species has been characterized recently (Barton et al. 1988). Because the results reported here indicate that the cellular expression of MSDl within both $\mathrm{N}$-CAM mRNA and polypeptide isoforms is indeed myotube specific, it is likely that MSDl is associated predominantly with the GPI-linked isoform found on the surface of myotubes. Of interest, however, is the observation that the MSDla exon is spliced individually into subpopulations of both muscle and brain N-CAM mRNAs. In the case of brain, MSDla may correspond to 
the alternative splicing event identified by Barthels et al. (1987) using S1 nuclease analysis. Indeed, the presence of a mouse homolog of MSDla, alternatively-spliced in mouse brain mRNAs encoding different N-CAM species, has been described (Santoni et al. 1989).

The biological consequences of MSD1 expression on $\mathrm{N}-\mathrm{CAM}$ ligand properties and myotube function in general remains, as yet, undefined. However, the region has structural characteristics similar to the so-called hinge region of immunoglobulin (Walsh 1988). It is rich in the amino acids proline, serine, and threonine and is located topographically membrane proximal to the array of five immunoglobulin homology units that run consecutively from the amino terminus of N-CAM polypeptides (Barton et al. 1988). Therefore, MSDl may act as a hinge region in N-CAM, resulting in the reorientation or altered conformation of the extracellular ligand binding domains. Indeed, direct electron microscopical visualization of embryonic chick brain N-CAM molecules using rotary shadowing techniques has revealed a 'dogleg' structure suggestive of a hinged molecule (Hall and Rutihauser 1987). In particular, the specific presence of the MSDla region in both brain and muscle N-CAMs and its predicted amino acid sequence producing a run of four proline residues is highly suggestive of such an open flexible structure. Furthermore, recent evidence has suggested that MSD1 may be a site of O-linked oligosaccharide attachment similar to the immunoglobulin hinge region (Walsh 1988). Alternatively, because the extent of N-CAM glycosylation influences N-CAM mediated cell aggregation profoundly (Rutishauser et al. 1988), it is possible that the introduction of O-linked oligosaccharide to isoforms expressing MSD1 may modulate directly N-CAM adhesive function or turnover of these forms in the membrane.

In conclusion, therefore, we have provided evidence here that diversity can be generated within the extracellular regions of myotube N-CAM isoforms as a result of developmentally regulated and tissue-specific alternative splicing events that may allow modulation of $\mathrm{N}$-CAM function in coordination with muscle differentiation. Although the precise function of MSDl remains to be elucidated, the pattern of expression of MSD1-containing N-CAMs in myotube cells is compatible with a role for these isoforms in motor axon outgrowth and neuromuscular junction formation, either during development or nerve regeneration. Comparative functional studies using eukaryotic gene transfer techniques and appropriate in vitro and in vivo models offer attractive approaches to examine the biochemical and cellular consequences of site-specific and deletion mutations of MSD1-bearing N-CAMs. In this way, hypotheses on the functional contribution of the N-CAM family in skeletal myogenesis may be put to the test directly.

\section{Material and methods}

S1 nuclease protection analysis

A deletion clone corresponding to $1-521$ bp of $\lambda 9.5$ in $\mathrm{M} 13$ mpl 8 (Dickson et al. 1987) was produced using exonuclease III and S1 nuclease (Henikoff 1984). A labeled probe was prepared subsequently from the deletion clone by extension from the universal priming site of the vector in the presence of $\left.{ }^{32} \mathrm{P}\right] \mathrm{dCTP}$. Probes were isolated following EcoRI digestion by alkaline agarose electrophoresis and electroelution (Maniatis et al. 1982). Probe $\left(10^{6} \mathrm{cpm}\right)$ was annealed to total RNA $(50 \mu \mathrm{g})$ from various sources (Dickson et al. 1987), digested with S1 nuclease, and analyzed on $4 \%$ wedge-gradient sequencing gels. Product sizes were determined using an end-labeled ladder $(123$ bp multimer) of molecular weight standards (BRL, Paisley, Scotland).

\section{Isolation and sequencing of genomic DNA clones}

A human genomic library in Charon 35 (provided by Dr. A. MacLeod/ was screened by plaque hybridization with N-CAM cDNAs, and phage clones were isolated by standard procedures. Physical mapping of restriction site and MSDl sequences was performed by single and double digestion of phage DNA, gel electrophoresis, and blot hybridization analyses (Maniatis et al. 1982). Nick-translated cDNA inserts or a 3 '-end-labeled oligonucleotide were used as probes (Davies et al. 1986). Appropriate restriction fragments from genomic clones were subcloned into M13mp18 and 19 vectors and sequences as described previously (Dickson et al. 1987).

Transfection of $3 T 3$ cells with N-CAM cDNA gene constructs

A full-length cDNA (CHBl) encoding a MSDl-containing 125 $\mathrm{kD}, \mathrm{GPI}$-linked human N-CAM has been described (Barton et al. 1988). To produce the corresponding MSDl deletion construct, use was made of the previously described cDNA, $\lambda 4.4$, which naturally contains such a deletion within a single EcoRI-KpnI fragment. The 3' EcoRI-HindIII fragment of CHB1 was first subcloned into pUC12 and its MSD1-containing E-K fragment substituted for that from $\lambda 4.4$. The remaining $5^{\prime}$ region of the gene contained within a single EcoRI fragment was then replaced, and appropriate recombinants selected by restriction site mapping.

For cell transfection studies, the entire coding regions of both wild-type and the deletion construct were excised as XmnIHindIII fragments and blunt-end ligated into the HindIII site of the eukaryotic expression vector $\mathrm{pH} \beta \mathrm{APr}-1-$ neo (Gunning et al. 1987). This vector drives inserted genes from the strong human $\beta$-actin promoter and contains appropriate splicing and polyadenylation signals and a linked neomycin-resistance gene. Sense-orientated N-CAM gene constructs were introduced into NIH-3T3 mouse fibroblasts as $\mathrm{CaPO}_{4}$ precipitates using the Pharmacia Cellphect Kit, and transfected clones selected in 500 $\mu \mathrm{g} / \mathrm{ml}$ Geneticin (Sigma) and screened for human N-CAM expression by immunostaining (Gower et al. 1988).

\section{Production and use of synthetic peptide antiserum}

A peptide corresponding to the predicted sequence of part of the MSD1 region of human N-CAM cDNA $\lambda 9.5$ (342-393 bases) was constructed using solid-phase procedures using FMOC chemistry (Burns et al. 1987). Peptide was conjugated to BSA emulsified in Freund's complete adjuvant and injected into rabbits at multiple intradermal and subcutaneous sites. Sera were tested by ELISA against peptide absorbed to microtiter plate wells. For immunostaining, cultures of human muscle cells were passaged and cultured in the presence of $10 \%$ fetal calf serum or $2 \%$ horse serum for 4 days to yield myoblast and myotube cultures, respectively (Walsh and Ritter 1981). Human skin fibroblasts and DRG cells (Dickson et al. 1982; Doherty 
and Walsh 1989) were cultured as described previously. Transfected mouse 3T3 cells were produced as described above. Cultures growing on glass coverslips were rinsed with serum-free SATO medium (Doherty and Walsh 1989) and incubated in a $10 \% \mathrm{CO}_{2}, 90 \%$ air environment at $37^{\circ} \mathrm{C}$ for $60 \mathrm{~min}$ in the presence and absence of neuraminidase $(1 \mathrm{U} / \mathrm{ml}$; Sigma type $\mathrm{X})$. Primary antibodies were then added directly at appropriate dilution and the immunostaining analyses completed as described previously (Walsh and Ritter 1981). The anti-MSDlb peptide serum was used at a $1: 50$ dilution in combination with mouse monoclonal antibodies either to human N-CAM $\mid 1: 500$ dilution of ascities fluid) or human fibronectin (1:100 dilution of ascites; Walsh et al. 1981).

\section{Acknowledgments}

This work was supported by Muscular Dystrophy Group of Great Britain, Wellcome Trust and Brain Research Trust. F.S.W. is a Wellcome Trust Senior Lecturer. We thank L. Kedes for generously supplying the pßAPr-1-neo expression vector.

\section{References}

Barthels, D., M-J. Santoni, W. Wille, C. Ruppert, J-C. Chaix, M-R Hirsch, J-C Fontecilla-Camps, and C. Goridis. 1987. Isolation and nucleotide sequence of mouse N-CAM cDNA that codes for a $\mathrm{Mr} 79,000$ polypeptide without a membrane-spanning region. EMBO J. 6: 907-914.

Barton, C.H., J.G. Dickson, H.J. Gower, L.H. Rowett, W. Putt, V.L. Elsom, S.E. Moore, C. Goridis, and F.S. Walsh. 1988. Complete sequence and in vitro expression of a tissue-specific phosphatidylinositol-linked N-CAM isoform from skeletal muscle. Development 104: 164-173.

Burns, D.L., S.Z. Hausman, W. Lindner, F.A. Robey, and C.R. Manclark. 1987. Structural characterization of pertussis toxin A subunit. I. Biol. Chem. 262: 17677-17682.

Covault, J., J.P. Merlie, C. Goridis, and J.R. Sanes. 1986. Molecular forms of N-CAM and its RNA in developing and denervated skeletal muscle. J. Cell. Biol. 102: 731-739.

Cunningham, B.A. 1986. CAMs: A new perspective on molecular embryology. Trends Biochem. Sci. 11: 423-426.

Cunningham, B.A., J.J. Hemperley, B.A. Murray, E.A. Prediger, R. Brackenbury, and G.M. Edelman. 1987. Neural cell adhesion molecule: Structure, immunoglobulin-like domain, cell surface modulation and alternative RNA splicing. Science 236: 799.

Davies, L.G., M.D. Dibner, and J.F. Battey. 1986. Basic methods in molecular biology. Elsevier, New York.

Dickson, J.G., T.P. Flanigan and F.S. Walsh. 1982. Cell surface antigens of human foetal brain and dorsal root ganglion cells in tissue culture. In Human motor neuron diseases (ed. L.P. Rowland), pp. 435-451, Raven Press, New York.

Dickson, G., H.J. Gower, C.H. Barton, H.M. Prentice, V.L. Elsom, S.E. Moore, R.D. Cos, C. Quinn, W. Putt, and F.S. Walsh. 1987. Human muscle neural cell adhesion molecule $(\mathrm{N}-\mathrm{CAM})$ : Identification of a muscle-specific sequence in the extracellular domain.

Doherty, P. and F.S. Walsh. 1988. K-252a specifically inhibits the survival and morphological differentiation of NGF-dependent neurons in primary cultures of human cell root ganglia. Neurosci. Lett. 96: 1-6.

Edelman, G.M. (1986) Cell Adhesion molecules in neural histogenesis. Annu. Rev. Physiol. 48: 417-430.

Edelman, G.M. and J.P. Thiery. eds. 1985. The cell in contact: Adhesions and junctions as morphogenetic determinants. Wiley, New York.
Finne, J., U. Finne, H. Deagostini-Bazin, and C. Goridis. 1983. Occurrence of $\alpha 2-8$ linked polysialosyl unites in a neural cell adhesion molecule. Biochem. Biophys. Res. Comm. 112: 482-487.

Gennarrini, G., M.R. Hirsch, H.T. He, M. Hirn, J. Finne, and C. Goridis. 1986. Differential expression of mouse N-CAM mRNA species during brain development and in neural cell lines. I. Neurosci. 6: 1983-1990.

Gower, H.J., C.H. Barton, V.L. Elsom, J. Thompson, S.E. Moore, J.G. Dickson, and F.S. Walsh. 1988. Alternative splicing generates a secreted form of N-CAM in muscle and brain. Cell 55: 955-964.

Gunning, P., J. Leavitt, G. Muscat, S-Y Ng, and L. Kedes. 1987. A human $\beta$-actin expression vector system directs highlevel accumulation of antisense transcripts. Proc. Natl. Acad. Sci. 84: 4831-4835.

Hall, A.K. and U. Rutishauser. 1987. Visualization of neural cell adhesion molecules by electron microscopy..MDBU/ $J$. Cell. Biol..MDBU/ 104: 1579-1586.

He, H.T., J. Barbet, J.-C. Chaix, C. Goridis. 1986. Phosphatidylnositol is involved in the membrane attachment of N-CAM-120, the smallest component of the neural cell adhesion molecule. EMBO I. 5: 2489-2494.

Hemperley, J.J., G.M. Edelman, and B.A. Cunningham. 1986. cDNA clones of the neural cell adhesion molecule (N-CAM) lacking a membrane-spanning region consistent with evidence for membrane attachment via a phosphatidylinositol intermediate. Proc. Natl. Acad. Sci. 83: 9822-9826.

Henikoff, S. 1984. Unidirectional digestion with exonuclease III creates targeted breakpoints for DNA sequencing. Gene 28: $351-359$.

Hoffman, S., B.C. Sarkin, P.C. White, R. Brackenbury, R. Mailhammer, U. Rutishauser, B.A. Cunningham, and G.M. Edelman. 1982. Chemical characterization of a neural cell adhesion molecule purified from embryonic brain membrane. J. Biol. Chem. 257: 7720-7729.

Maniatis, T., E.F. Fritsch, and J. Sambrook. 1982. Molecular cloning: A laboratory manual, Cold Spring Harbor Laboratory, Cold Spring Harbor, New York.

Moore, S.E., J. Thompson, V. Kirkness, J.G. Dickson, and F.S. Walsh. 1987. Skeletal muscle neural cell adhesion molecule (N-CAM): Changes in protein and mRNA species during myogenesis of muscle cell lines. J. Cell. Biol. 105: 13771386.

Nybroe, O., D. Linnemann, and E. Bock. 1988. N-CAM biosynthesis in brain. Neurochem. Int. 12: 251-262.

Owens, G.C., G.M. Edelman, and B.A. Cunningham. 1987. Organization of the neural cell adhesion molecule (N-CAM) gene: Alternative exon usage as the basis for different membrane associated domains. Proc. Natl. Acad. Sci. 84: 294298.

Rieger, F., M. Nicolet, M. Pincon-Raymond, M. Murawsky, G. Levi, and G.M. Edelman. 1988. Distribution and role in regeneration of N-CAM in the basal laminae of muscle and Schwann cells. J. Cell. Biol. 107: 707-719.

Rutishauser, U. 1986. Differential cell adhesion through spatial and temporal variations of the neural cell adhesion molecule. Trends Neurosci. 9: 374-378.

Rutishauser, U., M. Grumet, and G.M. Edelman. 1983. N-CAM mediates initial interactions between spinal cord neurons and muscle cells in culture. $J$. Cell. Biol. 97: 145-152.

Rutishauser, U., J.P. Thiery, R. Brackenbury, and G.M. Edelman. 1978. Relationship of the surface molecule CAM to cell adhesion and the development of histotypic patterns. I. Cell. Biol. 79: 371-381.

Rutishauser, U., A. Acheson, A.K. Hall, D.M. Mann, and J. 
Sunshine. 1988. The neural cell adhesion molecular (NCAM) as a regulator of cell-cell interactions. Science 240: $53-57$.

Sadoul, R., M. Hirn, H. Deagostini-Bazin, G. Rougon, and C. Goridis. 1983. Adult and embryonic neural cell adhesion molecules have different binding properties. Nature 304: 347-349.

Santoni, M.J., D. Barthels, G. Vopper, A. Boned, C. Goridis, and W. Wille. 1989. Differential exon usage involving an unusual splicing mechanism generates at least 8 types of $\mathrm{N}-\mathrm{CAM}$ cDNA in mouse brain. $E M B O J$. (in press).

Santoni, M.J., D. Barthels, J.A. Barbas, M-R Hirsch, M. Steinmetz, C. Goridis and W. Willie. 1987. Analysis of cDNA clones that code for the transmembrane forms of the mouse neural cell adhesion molecule (N-CAM) are generated by alternative RNA splicing. Nucleic Acids Res. 13: 8612-8640.

Shapiro, M.B. and P. Senapathy. 1987. RNA splice junctions of different classes of eukaryotes: Sequence statistics and functional implications in gene expression. Nucleic Acids Res. 15: 7155-7174.

Silver, J. and U. Rutishauser. 1984. Guidance of optic axons in vivo by a preformed adhesive pathways and neuroepithelial endfeet. Dev. Biol. 106: 486-499.

Small, S.J., G.E. Shull, M-J. Santoni, and R. Akeson. 1987. Identification of a cDNA clone that contains the complete coding sequence for a $140-\mathrm{kD}$ rat N-CAM polypeptide. $/$. Cell. Biol. 105: 2335-2345.

Takeichi, M. 1988. The cadherins: Cell-cell adhesion molecules controlling animal morphogenesis. Development 102: 639655.

Thanos, S., F. Bonhoeffer, and U. Rutishauser. 1984. Fibre-fibre interaction and tectal cues influence the development of chick retinotectal projection. Proc. Natl. Acad. Sci 81: 1906-1910.

Tosney, K.W., M. Watanabe, L Landmesser, and U. Rutishauser. 1986. The distribution of N-CAM in the chick hindlimb during axon outgrowth and synaptogenesis. Dev. Biol. 114: 437-452.

Walsh, F.S. 1988. The N-CAM gene is a complex transcriptional unit Neurochem. Int. 12: 262-267.

Walsh, F.S. and M.A. Ritter. 1981. Surface antigen differentiation dining human myogenesis in culture. Nature 289: 60 .

Walsh, F.S., S.E. Moore, and S. Dhut. 1981. Monoclonal antibody to fibronectin: Production and characterization using human muscle cultures. Dev. Biol. 84: 121-132. 


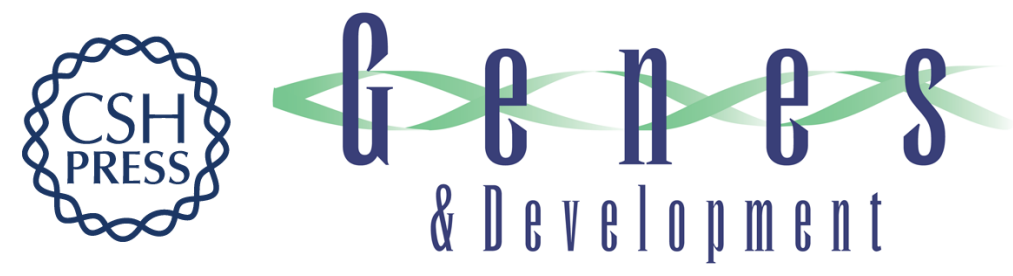

\section{Alternative splicing of the neural cell adhesion molecule gene generates variant extracellular domain structure in skeletal muscle and brain.}

J Thompson, G Dickson, S E Moore, et al.

Genes Dev. 1989, 3:

Access the most recent version at doi:10.1101/gad.3.3.348

References This article cites 36 articles, 16 of which can be accessed free at: http://genesdev.cshlp.org/content/3/3/348.full.html\#ref-list-1

License

Email Alerting Service

Receive free email alerts when new articles cite this article - sign up in the box at the top right corner of the article or click here.

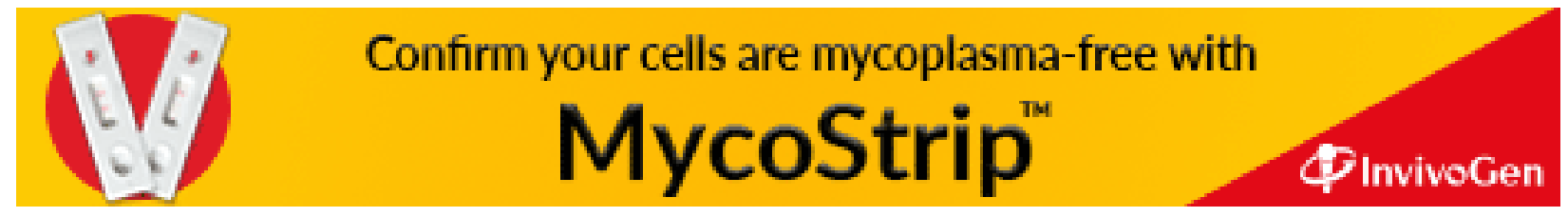

